\title{
Librarians in cyberspace
}

\author{
A pilot's view
}

by Deborah J. Grimes

I am a library director, which means that I don't get to spend as much time with our students as I would like. But some of my best days are those when I go out of my office to work with students one-on-one and find that I've still got it-I can still answer obscure reference questions and I can inevitably find good sources of information for them.

Last week, for example, I helped a student find several biographical references, both print and electronic, on Jesse Jackson. I was the first person to teach her that the Internet is not one source (as in, "You must have more than one source of information for this assignment"). I taught her that the Internet is

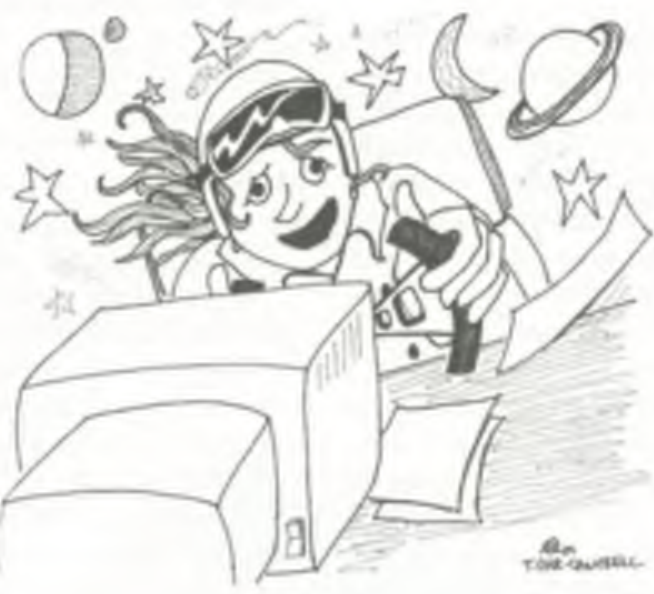
not a single source, as she thought, but a stream of sources flowing past like planets and meteors and, alas, space junk, as we zoom through cyberspace looking for what we need.

I saw myself as a kind of cyberpilot, navigating the jetstreams of information and connecting my passenger safely with her infor- mation destinations. We found good sources of information, such as the Rainbow/PUSH Coalition page with its biographical text on Jackson, as well as articles from national newspapers. We also found the junk-or what would be considered junk for a college student-elementary school Web assignments, dead links, and undocumented Web pages. Sometimes when I work with students, in fact, oftentimes, I go beyond the mere pickup and delivery of information and actually teach them how to choose information destinations judiciously and how to use them effectively. But it is the cyberpilor image that catches my fancy.

Don't get me wrong. I'm no video game techie. The last video game I played was Pac Man, and, because of what I conclude can only be a spatial learning disability, I inevitably ran right into the monsters instead of away from them. Needless to say, my game times were very brief. My information flight log, however, is quite lengthy, and I'm generally on target

\section{About the author}

Deborah J. Grimes is director of library services at Shelton State Community College in Tuscaloosa, Alabama; e-mail: dgrimes@shelton.cc.al.us 
when it comes to identifying and locating information sources.

\section{Librarians as cyberpilots}

Like pilots, librarians receive special training and instruction in using specialized equipment and in performing complicated tasks. Although we are not involved in the life-and-death situations that are the daily trade of pilots, like them, we find that much of our success is based on skill and intuition.

Service and duty ethics are as strong among librarians as among the military. We train and practice on information flight simulators before going out with real passengers or cargo. We pick up hot information spots on our radar and log them for others to find; we are continually mapping and expanding our cybernetic horizons and destinations. We rely heavily on a ground crew of support staff who provide the infrastructure we need to do our work and we rely on the information traffic controllers in our organizations who serve as team leaders and department heads.

We conduct our pre-flight briefings by discussing information targets with other cyberpilot librarians; we have in-flight commentary between fliers or after-flight debriefings when we discuss a particular topic or a particularly difficult search with other cyberpilot/librarians. We even chew the cyberspace fat with our colleagues by bragging about our successes ("Yes, I did find a line drawing of a wart hog online"), our unusual encounters ("Yes, the student who asked me if I thought he was schizophrenic was satisfied with the treatment information I found"), and our near misses ("I was ready to give up on biographies of famous cosmetologists when I tried one more search term and found three magazine articles"), and the new frontiers and cyberoutposts we discover ("Let me tell you about this great site I found today").

We chart our flights so that other cyberpilot/librarians (and our patrons) can find their ways to some of our favorite information destinations (hence, the booming industry in virtual reference desks and online subject guides). There's actually a cyberpilot's license on the Web. It is proposed by $R$. W. Burniske as a way to teach children not only how to use computers, e-mail, search engines, and message forums, but also to teach them about ethics and acceptable use of Web resources. ${ }^{1}$ Maylue we should consider something along the same lines for ourselves, as well as for our students.

\section{Top gun}

On my best days, when I am flying free in cyberspace, and when my computer and my imagination really get going, I can actually imagine the g-forces pushing me back into my ergonomically designed cockpit (Okay, it's really just a desk with a keyboard extension, but go with me).

And like Tom Cruise, I've learned never to leave my wing man-never leave another cyberpilot/librarian alone when there's a horde of information-hungry students around. So, if you find me in my office in my leather flight jacket and aviator glasses, call me by my cybernickname (Dewey? LC? Yahoo!? Google?) and remember that, as a library director, I have responsibilities on the flight deck as well as in cyberspace. But, on those days when I find I can navigate with the best of the best, even a library director dreams of being top gun in information cyberspace.

\section{Note}

1. See http://www.techlearning.com/db_ area/archives/WCE/archives/burniske.htm for "The Cyberpilot's License; A Modest Proposal for Educational Curricula," by R. W. Burniske and http://www.cwrl.utexas.edu/ burniske/ $\mathrm{cpl} /$ for an online prototype of Burniske's proposed license.

("Collection ... continued from page 279) responsible for getting out RFPs and handling bids), or people in the contracting company who want to focus on completing the project as rapidly and efficiently as possible, may not view collection protection as a high priority. Therefore, it is important that a library staff embarking on a renovation project understands collection protection issues and make the commitment to include a person responsible for the safety and protection of the collection at all stages of planning and implementation of the project. Failure to do so could leave the library with a nice building housing a seriously damaged collection. 
www.booksinprint.com

The definitive source for

unbiased bibliographic data

- more than 3 million records

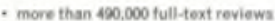

- audio and video record:

- ast*of-print tooks

- sleck availability from majer supptiers

- direct searching on file of our 300,000 pub.

lishers, diatributorn, and wholesaiers

- author biographies

- over 300 took, audio, and video awards

There's no doubt that technology is changing the way libraries work, and we're making sure it works in your favor. We've taken the three industry standards, Books In Print", Ulrich's International Periodicals Directory ", and Literary Market Place" to the Web, so now you can click open the world with our unrivaled, up-to-date information for greater convenience than ever before.

\section{click open the world"...}

and discover all the options available in the all new booksinprint.com "2000, ulrichsweb.com ", and literarymarketplace,com". Offering navigational ease and extremely friendly interfaces, our sleek new Web-based platforms will give you the information you need faster, easier, and with more frequent updates than ever before.

\section{...or go by tha book}

if you prefer your data in book or CD-ROM form, those media are still available, too, complete with all the features that have made Bowker the number one source for libraries for more than 128 years

\section{ia}

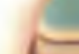

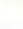

